\title{
Affective, physiological, and attitudinal consequences of audience presence
}

\author{
RICHARD J. BORDEN \\ Purdue University, West Lafayette, Indiana 47907 \\ CLYDE HENDRICK \\ Kent State University, Kent, Ohio 44240 \\ and \\ JOHN W. WALKER \\ Purdue University, West Lafayette, Indiana 47907
}

\begin{abstract}
Numerous social facilitation studies have shown that the presence of an audience increases the emission of dominant responses in a variety of learning-performance situations. Extending these notions to attitude change, the effects of audience observation should result in enhanced persuasion whenever acceptance tendencies following a persuasive message are dominant. A persuasive communication which had previously been shown to produce large acceptance responses was presented to male and female subjects who were either alone or in the presence of an audience. Contrary to social facilitation expectations, subjects indicated more acceptance of the communication when they were alone. Results of self-report affect measures showed that subjects felt significantly more anxious and hostile when they were being observed. Autonomic measures (heart rate and skin conductance) tended to be unrelated to the audience manipulation, subjects' feeling states, and their attitudinal responses. Apparently, subjects' attitudinal responses were mediated more by competing feelings and cognitions, noncompliance tendencies, and response moderation than mechanisms of drive or arousal.
\end{abstract}

The assumption that the presence of others can influence the thoughts and behavior of an individual was perhaps the original cornerstone of social psychology. Many texts consider Triplett's (1897) research on pacemaking and competition as the first social psychological experiment. Although the work of Triplett and others (Allport, 1920; Dashiell, 1930; Husband, 1931; Pessin, 1933; Travis, 1925) demonstrated that the presence of others can exert a powerful influence on individual behavior, little progress was made toward theoretical clarification until an important paper by Zajonc (1965).

Zajonc proposed that the presence of others increases drive (D), which is assumed to have an energizing effect on existing response tendencies. Increased drive should lead to the enhancement of dominant responses, and thus the improvement of performance on simple or well-learned tasks, but a decrement in learning or performance of difficult or novel tasks. This theory accounts for both positive and negative results in the social facilitation literature and has been supported in subsequent research (Cottrell, Rittle, \& Wack, 1967; Hency \& Glass, 1968; Zajonc \& Sales, 1966).

This research was supported by NIMH Grant No. 20388-01. We thank Tony Booth and Pam Manus who served as the observers. Request reprints from: Richard J. Borden, Department of Psychological Science. Purdue University, West Lafayette. Indiana 47907.
Consistent with the social facilitation position, the presence of others has been found to result in increased levels of human physiological activity as measured by palmar sweating (Martens, 1969), pupillary response (Simpson \& Molloy, 1971), and vocal stress (Brenner, Note 1).

Finally, the presence of others has also been shown to have a marked influence on the subjective feelings of individuals. From research in the areas of embarrassment, stage fright, and audience anxiety, investigators report the not too surprising result that people report experiencing more anxiety, tension, embarrassment, and so on, prior to and during a public performance than when they are not involved in public activities (For reviews, see Clevenger, 1959; Paivio, 1965).

In general, then, research from many areas clearly supports the contention that the presence of others has arousing properties. Evidence for such socially induced arousal comes from phenomenological reports, from measurements of physiological activity, and from the facilitation or disruption of overt behavior in the presence of others.

Hendrick (1968; Note 2) has developed an arousal-influenceability model which extends the notions of learning theory and social facilitation to the persuasion situation and makes specific predictions concerning the effects of arousal on attitude change. According to this model, generalized arousal should 
seven-item speech evaluation form, a mood rating scale, a 10 -item multiple-choice quiz to assess recall, and a four-item attitude scale. The mood scale consisted of 16 adjectives tapping four general mood states: hostility (angry + irritated + annoyed + grouchy), happiness (carefree + playful + cheerful), loss of control (dazed + overwhelmed + helpless + irresponsible), and anxiety (alarmed + jittery + afraid + restless + tense). The attitude measure consisted of four 15-point scales assessing acceptance of the communication.

\section{RESULTS}

\section{Communication Evaluation}

Analyses of variance on the evaluations of the communications revealed that females considered the material to be more difficult than males $[F(1,20)=10.14, p<.05]$, and subjects who were observed during the presentation felt that it was less well presented than subjects who were not observed $[F(1,20)=4.63, p<.05]$. Otherwise, no significant effects for sex, observer's presence, or interactions of these two factors were obtained for the ratings of how well the communication was presented, or how difficult, interesting, truthful, reasonable, biased, or scientific it was.

\section{Mood Ratings.}

Subject's ratings of anxiety indicated that they felt considerably more anxious when they were being observed, $F(1,20)=8.37, p<.01$. Feelings of hostility were also significantly higher when observers were present, $F(1,20)=6.79, p<.01$. Measures of happiness and loss of control were unaffected by the presence of observers.

\section{Physiological Measures}

Heart rate. Heart-rate samples were taken at seven points during each session. The first was a 10-sec baseline sample taken immediately before the introduction of the audience manipulation. Five 1-min samples were taken during each minute of the communication, and an additional 1-min sample was obtained while the subject was filling out the mood rating scales. These measures were then subjected to a groups by periods analysis of variance. 2

According to the analysis of variance, there was a significant periods effect, $F(6,120)=4.60, p<.0005$, with significant quadratic, $F_{\text {quad }}(1,20)=71.25$, $\mathrm{p}<.0001$, and cubic components, $F_{\text {cubic }}(1,20)=$ $10.60, p<.0001$. These components reflect significant increases in heart rate associated with the onset of the communication, a reduction during the communication, and a final increase as the subject responded to the self-report measures. There was no overall difference between males' and females' heart rate or interaction of sex with repeated measures. Subjects in the audience condition did tend to have higher heart rate than alone subjects, but the overall effect was not significant. There was, however, a marginally significant interaction of audience presence and repeated measures $F_{l i n}(1,20)=3.61, p=.07$, with subjects in the alone condition showing more heart-rate increases across periods than subjects in the audience condition. No interactions of Sex by Audience, or Sex by Audience by Periods were obtained.

Skin conductance. The epidermal response was measured in resistance units which were subsequently converted into micromhos of conductance (micromho $1 / \Omega \times 1,000,000)$. Five conductance samples were taken from each subject. The baseline sample was obtained by averaging the conductance scores at the beginning and end of the baseline heart-rate sample. Similarly, three conductance values were calculated at the beginning and end of Minute 1, Minute 3, and Minute 5 of the communication. Finally, a measure was taken as the subject filled out the mood scales by averaging the skin conductance values corresponding to the beginning and end of the 1-min heart-rate sample.

The skin conductance scores were analyzed with a groups by periods analysis of variance. As with heart rate, there was a highly significant periods effect, $F(4,80)=4.58, p<.0005$. Unlike heart rate, however, skin conductance decreased with the onset of the communication, but did increase when subjects filled out the questionnaires following the communication. The components analysis revealed a significant quadratic trend, $F_{\text {quad }}(1,20)<33.85, p=.0001$, but no linear or cubic trends. Finally, no significant effects were associated with subject's sex or audience presence, and neither of these factors interacted with repeated measures of conductance.

\section{Attitude Change and Recall}

The pattern of attitude and recall scores for each of the two communications were similar. Consequently, they were combined and analyzed together.

No sex differences were obtained on either the recall or acceptance scores. Audience presence, however, significantly affected both measures. There was greater acceptance of the communications by alone subjects than by subjects who were in the audience condition, $F(1,20)=5.75, p<.025$. Subjects in the alone condition also recalled significantly more of the messages than did subjects who were observed, $F(1,20)=4.74, p<.05$. No significant Sex by Audience presence interactions emerged for either the attitude or recall measures.

\section{Factor Analysis}

Because of the apparently powerful effect of audience presence on moods, recall, and attitude, but not the physiological measures, a factor analysis was performed on the pooled sample to attempt to delineate more clearly the relationship between the audience manipulation and these measures.

In the present case, the factor analysis was used primarily as a descriptive tool to indicate which dependent variables loaded together with, and which loaded separately from, the main independent 
lead to increased persuasion whenever the tendency to accept a communication is greater than the tendency to reject (e.g., immediately following a one-sided communication in which acceptance cues should be dominant).

Hendrick and Shaffer (1970) tested the model's main hypothesis using one type of extraneous arousal. Subjects heard a persuasive communication presented at average volume (low arousal) or very high -volume (high arousal). Manipulation checks revealed that subjects in the high volume condition felt significantly more aroused than subjects in the normal volume condition. Contrary to predictions, however, results showed that females were more persuaded under low arousal than under high arousal, whereas the attitudes of males were unaffected. A similar pattern of results was also obtained by Hendrick and Borden (1970). In their study, extraneous arousal was manipulated by expectation of either painful electric shock (high arousal) or mild shock (low arousal). It should be noted that in both of these studies, subjects reported that the high-arousal manipulations were also highly aversive. Possibly, the arousal-persuasibility relationship breaks down when subjects label their arousal state as aversive.

In a recent study using false arousal feedback, Hendrick, Geisen, and Borden (1975) found that subjects who viewed a meter showing them to be highly aroused were more persuaded than subjects who received moderate arousal feedback. Similar findings were also obtained by Geisen and Hendrick (1974) when the high false arousal feedback was labeled as either positive or negative arousal. Thus, the simple perception of increased arousal, whether pleasant or unpleasant, facilitates attitude change and the results from studies using this methodology support the arousal-persuasibility hypothesis. When the arousal is induced by extraneous situational manipulations (e.g., threatening subjects with painful electric shocks or having them listen to sonorous tape recordings) cognitions or feelings states that interfere with acceptance responses may be produced. In other words, a strong arousal-producing situation may elicit additional responses that are not produced by the "information of arousal" provided in the arousal feedback situation.

The present study was one of a series in a research program designed to test the arousal-persuasibility relationship with several sources of extraneous arousal. Arousal in the present study was induced by audience observation. Subjects heard a persuasive communication either in solitude or while being observed by a small audience. Since other studies in this series have found interactions with subject's sex (Hendrick \& Borden, 1970; Hendrick \& Shaffer, 1970), this factor was also included. In view of the fact that subjects in these studies also reported strong negative emotions to the extraneous arousal manipulations, each subject's feelings, perceptions of the situation, and attentiveness to the communication were also assessed in the present study.

Another important issue concerns the measurement of arousal. Although this term has a wide usage, there are researchers who have argued for a single arousal dimension (Duffy, 1962), others for two dimensions (Routtenberg, 1968), and still others for three separate arousal systems (Lacey, 1967). Moreover, separate autonomic measures are sometimes found to intercorrelate well (Lazarus, Speisman, \& Mordkoff, 1963) and sometimes not (Taylor \& Epstein, 1967). To better understand the interrelationships among various measures of arousal, two autonomic measures (heart rate and skin conductance) were monitored throughout the sessions, in addition to measures of the subject's self-reported arousal. This multimeasurement procedure was utilized in order to determine which measure of arousal provides the best predictor of resultant persuasion.

\section{METHOD}

\section{Subjects and Procedure}

Twelve male and twelve female students from a large introductory psychology class served individually as subjects. Each subject was met by the experimenter who explained that the research was concerned with the measurement of "physiological activity during listening." He indicated that a brief excerpt from a lecture series on health practices would be heard. Following the excerpt, the subject would be required to respond to a number of questionnaires assessing his/her comprehension, emotional reactions, opinions toward the speech, as well as a variety of other subjective measures.

The subject was seated in a large comfortable chair, and the physiological recording electrodes were attached. The experimenter then left the room for 5 min to adjust the polygraph and allow the subject's physiological reactions to stabilize.

After the baseline measurements were established, the audience manipulation was introduced. For half of the subjects, the experimenter reentered the room accompanied by another male and female. He explained to the subject that these persons were' in another psychology class which required "observation points" much like the subject's participation points and that they would be watching his (or her) responses for a later class discussion. The two (confederate) observers were seated six feet directly in front of and facing the subject. The experimenter then left the room, and the tape recorded persuasive communication was played through a loudspeaker to the subject and the observers.

In the alone condition, the experimenter reentered the room following the baseline measurement, briefly informed the subject that the tape recorded lecture was about to begin, and then left.

\section{Apparatus}

Subject's heart rate and skin conductance were monitored with a Grass Model 7 polygraph. Basal conductance changes were transduced with silver-silver chloride electrodes attached to the palmar and dorsal surfaces of the subject's left hand and preamplified with a 7P1 low-level dc preamplifier. The subject's heart rate was monitored with a 7P4 preamplifier. The heart rate response was detected via a Grass PTTI photoelectric transducer attached to the forefinger of the subject's left hand.

\section{Communications and Questionnaires}

As in prior studies in this research program, subjects heard one of McGuire's (1964) communications on health practices. Half of the subjects in each condition heard "Some dangers of excessive tooth brushing"; the remaining subjects heard "Some drawbacks involved in the use of penicillin." Each communication lasted exactly $5 \mathrm{~min} .^{1}$.

Immediately following the communication, the subject filled out a 
Table 1

Factor Analysis of the Pooled Sample

\begin{tabular}{lrrrc}
\hline & \multicolumn{4}{c}{ Factor } \\
\cline { 2 - 4 } Variable & I & II & III & $h^{2}$ \\
\hline Subject's sex & .14 & .55 & .65 & 74.5 \\
Audience-alone & .73 & -.09 & -.08 & 55.1 \\
Recall & -.75 & .08 & -.23 & 63.1 \\
Attitude & -.78 & .19 & .12 & 66.0 \\
Hostility & .79 & .29 & .17 & 74.2 \\
Happiness & -.05 & -.14 & .85 & 74.9 \\
Loss of control & .43 & .46 & -.01 & 39.6 \\
Anxiety & .73 & .54 & -.19 & 85.6 \\
Conductance & -.01 & .63 & .07 & 40.6 \\
Heart rate & -.26 & .82 & -.14 & 77.1 \\
Percent of total variance & 31.45 & 20.49 & 13.13 & {$[65.1]$} \\
\hline
\end{tabular}

manipulations. Consequently, in addition to the four mood states, recall, attitude, and physiological measures, the subject's sex and experimental condition were also included as variables to be factored.

Examination of Table 1 indicates that the factor analysis revealed three factors which account for $65 \%$ of the variance. 3 Interestingly, hostile feelings, anxiety, recall, and attitude measures loaded heavily on the first factor along with the audience variable. The second factor consisted of the two physiological measures with moderate loadings of anxiety and feelings of loss of control. Finally, subject's sex and feelings of happiness appeared on the third factor.

\section{DISCUSSION}

At the outset of this study, it was expected that subjects who were watched by two observers would show more signs of physiological arousal and greater acceptance of a persuasive communication than subjects who heard the same communication in solitude. If anything, the results were opposite to these expectations. Although both physiological measures showed large and significant changes associated with the varying attentional demands of the experiment, autonomic reactivity was virtually unaffected by the observers' presence. Apparently, subjects responded to the observers' presence with hostility and anxious feelings which competed with or distracted from their primary task. Consequently, subjects in the audience condition comprehended less of the message and were less persuaded than alone subjects. Furthermore, as indicated by the factor analysis, the physiological measures were unrelated to the subjects' phenomenological experiences, recall ability, or final attitude.

\section{REFERENCE NOTES}

1. Brenner, M. Stagefright and Steven's law. Paper presented at the Meeting of the Eastern Psychological Association, 1974.

2. Hendrick, C. Arousal and attitude change. NIMH Grant proposal No. MH20388-01, 1971.

\section{REFERENCES}

Allport, F. H. The influence of the group upon association and thought. Journal of Experimental Psychology, 1920, 3, 159-182. Clevenger, T. A synthesis of experimental research in stage fright. Quarterly Journal of Speech, 1959, 45, 134-145.

Cottrell, N. D., Rittle, R. H., \& Wack, D. L. The presence of an audience and list type (competitional or noncompetitional) as joint determinants of performance in paired-associates learning. Journal of Personality, 1967, 35, 425-434.

GEISEN, M., \& HENDRICK, C. Effects of false positive and negative arousal feedback on persuasion. Journal of Personality and Social Psychology, 1974, 30. 449-457.
Henchy, T., \& Glass, D. C. Evaluation apprehension and the social facilitation of dominant and subordinate responses. Journal of Personality and Social Psychology, 1968, 10, 446-454.

HENDRICK, C. Fear arousal and attitude change: A general hypothesis. Unpublished theoretical manuscript. Kent State University, 1968.

Hendrick, C. \& Borden, R. J. Effects of extraneous fear arousal and birth order on attitude change. Psychonomic Science, 1970, 18, 225-226.

HENDRICK, C., \& ShAFFER, D. R. Effects of arousal and credibility on learning and persuasion. Psychonomic Science, 1970, 20. 241-243.

Hendrick, C., Geisen, M., \& Borden, R. J. False physiological feedback and fear arousing communications: Fear arousal versus fear reduction in the mediation of persuasion, Journal of Personality, 1975, 43, 196-214.

HusBand, R. W. Analysis of methods in human maze learning. Journal of Genetic Psychology, 1931, 39. 258-277.

LACEY, J. I. Somatic response patterning and stress: Some revisions of activation theory. In M. H. Appley \& R. Trumbull (Eds.), Psychological stress. New York: Appleton-Century-Crofts, 1967. Pp. 14-37.

Lazarus, R. S., Speisman, J. C., \& Mordkoff, A. M. The relationship between autonomic indicators of autonomic stress: Heart rate and skin conductance. Psychosomatic Medicine, 1963, 25, 19-30.

Martens, R. Palmar sweating and the presence of an audience. Journal of Experimental Social Psychology, 1969, 5, 371-374.

McGuire, W. J. Inducing resistance to persuasion. In L. Berkowitz (Ed.), Advances in experimental social psychology (Vol. 1). new York: Academic Press, 1964. Pp. 191-229.

PAIvio, A. Personality and audience influence. In B. Maher (Ed.) Progress in experimental personality research (Vol. 2). New York: Academic Press, 1965.

Pessin, J. The comparative effects of social and mechanical stimulation in memorizing. American Journal of Psychology, 1933. 45. 263-270.

Routtenberg, A. The two-arousal hypothesis: Reticular formulation and limbic system. Psychological Review, 1968, 75, 51-80.

Simpson, H. M., \& Molloy, F. M. Effects of audience anxiety il pupil size. Psychophysiology, 1971, 8, 491-496.

TAYlOR, S. P., \& EPSTEIN, S. The measurement of autonomic arousal. Psychosomatic Medicine, 1967, 29, 514-525.

Travis. L. E. The effect of a small audience on eye-hand coordination. Journal of Abnormal Social Psychology, 1925, 20, 142-146.

TRIPLETT, $\mathbf{N}$. The dynamogenic factors in pacemaking and competition. American Journal of Psychology, 1897, 9. 507-533.

ZAJONC, R. B. Social facilitation. Science, 1965, 149, 269-274.

Zajonc, R. B., \& SAles, S. M. Social facilitation of dominanı and subordinate responses. Journal of Experimental Social Psychology, 1966, 2, 160-168.

\section{NOTES}

1. Previous testing of these communications indicated that, on a 60 -point scale, the mean attitude of unexposed subjects was 16.6 , whereas the mean response of subjects who heard them while alone was 39.8. Thus, we feel confident that acceptance tendencies were dominant.

2.Analysis of covariance with subject's basal level as the covariate produced identical results for both heart rate and conductance.

3. An initial varimax rotation revealed additional factors. However, only Factors I, II, and II accounted, individually, for more than $5 \%$ of the variance. The loadings and communalities presented here are from the refactored sample with three factors extracted. Autonomic change scores (Baseline- $\overline{\mathrm{X}}$ Communication) were used in this analysis.

(Received for publication September 26, 1975.) 